\title{
Peak Speeds of Professional Football Players During Bouts of Non-curved, Manual Treadmill Sprints
}

\author{
Corey A. Peacock \\ Nova Southeastern University, cpeacock@nova.edu \\ Jacob Peacock \\ Nova Southeastern University, jp2716@mynsu.nova.edu \\ Jose Antonio \\ Nova Southeastern University, Jose.Antonio@nova.edu \\ Tobin Silver \\ Nova Southeastern University, tsilver@nova.edu \\ Gabriel J. Sanders \\ Northern Kentucky University, sandersg1@nku.edu
}

Follow this and additional works at: https://nsuworks.nova.edu/ijahsp

Part of the Medicine and Health Sciences Commons

\section{Recommended Citation}

Peacock CA, Peacock J, Antonio J, Silver T, Sanders GJ. Peak Speeds of Professional Football Players During Bouts of Non-curved, Manual Treadmill Sprints. The Internet Journal of Allied Health Sciences and Practice. 2021 Jan 01;19(2), Article 3.

This Manuscript is brought to you for free and open access by the College of Health Care Sciences at NSUWorks. It has been accepted for inclusion in Internet Journal of Allied Health Sciences and Practice by an authorized editor of NSUWorks. For more information, please contact nsuworks@nova.edu. 


\title{
Peak Speeds of Professional Football Players During Bouts of Non-curved, Manual Treadmill Sprints
}

\begin{abstract}
Purpose: Speed training and short distance sprints have become an essential component of preparation for professional football players. Current trends in speed training have included the application of noncurved, manual treadmills, as they may enhance peak speeds with less biomechanical stress. A lack of data currently exists in regards to the effectiveness of different settings and peak speed response. Therefore, we proposed to compare peak speeds during different settings of non-curved, manual treadmills. It was hypothesized that as resistance/incline increased, peak sprinting speeds would decrease and vice versa. Methods: Fourteen male professional football players $(27.14 \pm 3.11$ yrs., $183.93 \pm 8.52$ $\mathrm{cm}, 100.36 \pm 15.60 \mathrm{~kg}$ ) sprinted at peak speeds during four different incline/resistance bouts. Paired samples T-tests examined differences between bouts, and significance was set at $p \leq 0.008$. Results: A significant difference $(p<0.001)$ existed for peak speeds between each incline/resistance bout (i.e. INC15R8, INC15R5, INC20R3, INC20R1). Conclusions: The observed data differences existed between all bouts, indicating that as resistance and/or incline increased, peak speed decreased. This also indicated that as resistance and/or incline decreased, peak speed increased during sprint bouts in professional football players.
\end{abstract}

\section{Author Bio(s)}

Corey A. Peacock, PhD, is the Program Director and Associate Professor of Exercise and Sport Science in the Dr. Pallavi Patel College Of Health Care Sciences at Nova Southeastern University in Ft. Lauderdale, FL.

Jacob Peacock, is a student in the Dr. Kiran C. Patel College Of Osteopathic Medicine at Nova Southeastern University in Ft. Lauderdale, FL.

Jose Antonio, PhD, is an Associate Professor of Exercise and Sport Science in the Dr. Pallavi Patel College Of Health Care Sciences at Nova Southeastern University in Ft. Lauderdale, FL.

Tobin Silver, PhD, is an Associate Professor of Exercise and Sport Science in the Dr. Pallavi Patel College Of Health Care Sciences at Nova Southeastern University in Ft. Lauderdale, FL.

Gabriel J. Sanders, PhD, is a Program Director and Associate Professor at Northern Kentucky University in Highland Heights, KY. 


\title{
IIIAHSP \\ The Internet Joumnal of Allied Health Sciences and Practice \\ Dedicated to allied health professional practice and education \\ Vol. 19 No. 2 ISSN 1540-580X
}

\section{Peak Speeds of Professional Football Players During Bouts of Non-curved, Manual Treadmill Sprints}

\author{
Corey A. Peacock ${ }^{1}$ \\ Jacob Peacock ${ }^{1}$ \\ Jose Antonio ${ }^{1}$ \\ Tobin Silver ${ }^{1}$ \\ Gabriel J. Sanders 2
}

1. Nova Southeastern University

2. Northern Kentucky University

United States

\begin{abstract}
Purpose: Speed training and short distance sprints have become an essential component of preparation for professional football players. Current trends in speed training have included the application of non-curved, manual treadmills, as they may enhance peak speeds with less biomechanical stress. A lack of data currently exists in regards to the effectiveness of different settings and peak speed response. Therefore, we proposed to compare peak speeds during different settings of non-curved, manual treadmills. It was hypothesized that as resistance/incline increased, peak sprinting speeds would decrease and vice versa. Methods: Fourteen male professional football players $(27.14 \pm 3.11$ yrs., $183.93 \pm 8.52 \mathrm{~cm}, 100.36 \pm 15.60 \mathrm{~kg})$ sprinted at peak speeds during four different incline/resistance bouts. Paired samples T-tests examined differences between bouts, and significance was set at $p \leq 0.008$. Results: A significant difference $(p<0.001)$ existed for peak speeds between each incline/resistance bout (i.e. INC15R8, INC15R5, INC20R3, INC20R1). Conclusions: The observed data differences existed between all bouts, indicating that as resistance and/or incline increased, peak speed decreased. This also indicated that as resistance and/or incline decreased, peak speed increased during sprint bouts in professional football players.
\end{abstract}

Keywords: running, football, training 


\section{INTRODUCTION}

The National Football League (NFL) has relied heavily on measures of physical performance, including those tested at the NFL Combine. The various tests of power, strength, agility and speed have showed to impact both draft status and success. ${ }^{1,2}$ Creating methods of training to enhance performance in short sprints (9.14-m) and change of direction has been researched and determined very reliable in monitoring improvements in a variety of collegiate athletes. ${ }^{3,4}$ Speed has been researched extensively in regards to football, and has been determined as a focal point of performance enhancement. 2,5 The $36.58 \mathrm{~m}$ dash (40-yard) at the NFL combine has been associated to future NFL performance, as a faster time has shown positive relationships to being selected as an NFL all-pro. ${ }^{2}$ Recent changes in game rules even suggested that speed and acceleration have become vital characteristics sought out in football players. ${ }^{6}$

Recent trends in football player training have included such methods as both maximum ground speed training and maximum manual, treadmill training (curved or non-curved). Other research has followed to better understand these incline speed training effects. ${ }^{7,8}$ Maximum speed training comes with the risk of injuries; therefore, additional research has examined biomechanics of peak sprinting amongst ground and treadmill training.., 10 The majority of the manual treadmill research has analyzed a curved running surface. This data has identified alterations in biomechanics, but has yet to determine the effects of these changes on running performance. Fatigue has also played a major role in these alterations, as imbalances and biomechanical impacts arose during curved treadmill running. ${ }^{9}$

In conflict with these alterations in running mechanics, football training has recently included the use of a non-curved, manual treadmill for speed enhancement. There has been a lack of research data in regard to the non-curved, manual treadmill. Therefore, we intended to better analyze the function and effectiveness of different manual settings. We proposed to compare peak sprinting speeds during different settings of non-curved, manual treadmill bouts in professional football players. It was hypothesized that as resistance/incline increased, peak speeds would decrease. It was also hypothesized that as resistance/incline decreased, peak speeds would increase in football players.

\section{METHODOLOGY}

\section{Subjects}

The data-set included 14 male, professional football players $(27.14 \pm 3.11$ yrs.), with previous training utilizing a non-curved, manual treadmill. The inclusion criteria were professional football players (National Football League or Canadian Football League) who established medical clearance preceding off-season, training sessions. Exclusion criteria was established for those football players that were unable to pass medical examinations due to pre-existing or current health concerns and/or injuries.

\section{Procedures}

The professional football players arrived to the facility during the off-season cycle of their training year. All football players were instructed to refrain from physical activity 24 hours prior to any treadmill testing procedures. The football players were randomized and counterbalanced between four different sprinting bouts on a non-curved, manual treadmill (SHREDmill, Boca Raton, FL, USA). The peak speed $(\mathrm{m} / \mathrm{s})$ was recorded for each of the four sprinting bouts. The resistance and/or incline was adjusted for each trial in accordance with the manufacturer's recommendations and research, as the football players sprinted for peak speed (Figure 1). The four manual settings included a $15 \%$ incline and a resistance of eight (INC15R8), a 15\% incline and a resistance of five (INC15R5), 20\% incline and a resistance of three (INC20R3), and a 20\% incline with a resistance of 1 (INC20R1). The higher the incline percentage designated a greater, non-curved angle. The greater the resistance number designated an increased tension from the non-motorized belt, during peak sprinting bouts. This report of data was approved by the University's Institutional Review Board (IRB) and all football players provided consent to participate in the off-season training, including manual treadmill, sprinting bouts.

\section{Statistics}

Means and measures of variability were calculated for descriptive data and treadmill speeds. Subsequent the Shapiro-Wilk normality assessment, paired samples T-tests were used to analyze mean average differences between four running conditions (INC15R8, INC15R5, INC20R3, and INC20R1). All statistics were analyzed using Statistical Analysis Software (SPSS, Version 22.0, IBM INC., Armonk, NY) and significance was set at $p \leq 0.008$. 


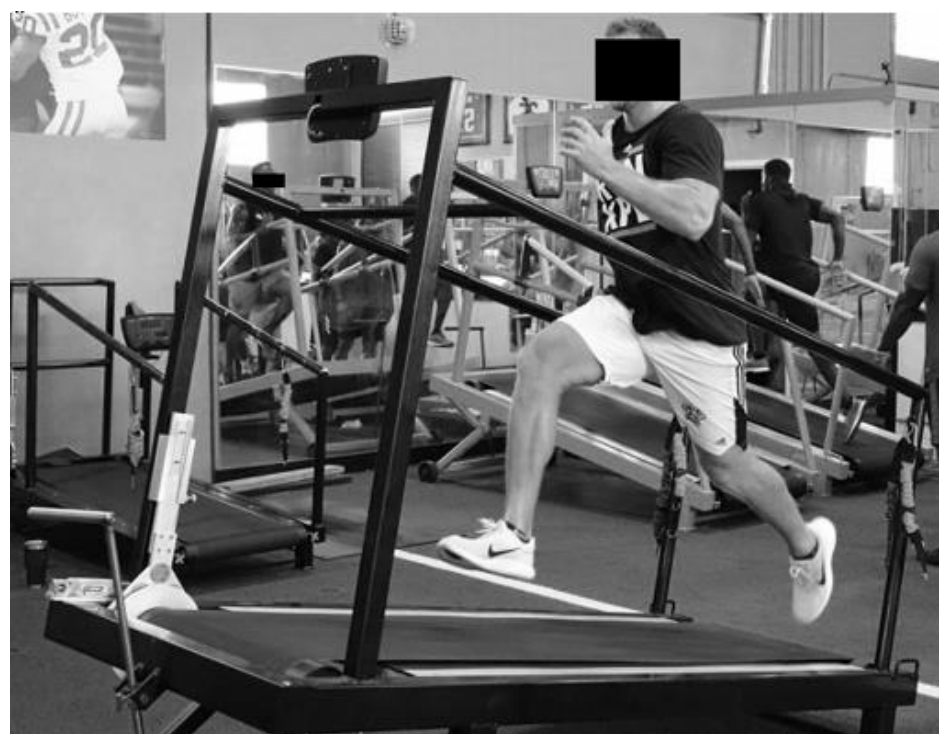

Figure 1. Non-Curved, Manual Treadmill Sprinting

\section{RESULTS}

All descriptive data including age, body height, body mass, and BMI was included for the group of male, professional football players in Table 1. All descriptive data of the peak speeds obtained during each of the four treadmill bouts was included in Table 2.

Table 1. Participant demographics

\begin{tabular}{|l|l|l|l|l|}
\hline & $\begin{array}{l}\text { age } \\
(\mathrm{yrs} .)\end{array}$ & $\begin{array}{l}\text { height } \\
(\mathrm{cm})\end{array}$ & $\begin{array}{l}\text { weight } \\
(\mathrm{kg})\end{array}$ & $\begin{array}{l}\text { BMl } \\
\left(\mathrm{kg} / \mathrm{m}^{2}\right)\end{array}$ \\
\hline $\begin{array}{l}\text { football players } \\
(\mathrm{n}=14)\end{array}$ & $27.14 \pm 3.11$ & $183.93 \pm 8.52$ & $100.36 \pm 15.60$ & $29.53 \pm 2.85$ \\
\hline
\end{tabular}

Data are Means \pm SD

Table 2. Descriptive data of treadmill peak speeds

\begin{tabular}{|l|l|l|l|l|}
\hline & $\begin{array}{l}\text { INC15R8 } \\
(\mathrm{m} / \mathrm{s})\end{array}$ & $\begin{array}{l}\text { INC15R5 } \\
(\mathrm{m} / \mathrm{s})\end{array}$ & $\begin{array}{l}\text { INC20R3 } \\
(\mathrm{m} / \mathrm{s})\end{array}$ & $\begin{array}{l}\text { INC20R1 } \\
(\mathrm{m} / \mathrm{s})\end{array}$ \\
\hline $\begin{array}{l}\text { football players } \\
(\mathrm{n}=14)\end{array}$ & $6.73 \pm 0.38$ & $7.21 \pm 0.40$ & $7.64 \pm 0.30$ & $8.12 \pm 0.28$ \\
\hline
\end{tabular}

Data are Means \pm SD

T-test results, which compared peak speeds at different incline/resistance settings was included in Table 3. The data analysis revealed a significant difference $(P<0.001)$ between INC15R8 and INC15R5, INC20R3, and INC20R1. The data analysis also revealed a significant difference $(P<0.001)$ between INC15R5 and INC20R3, INC20R1. Finally a significant difference $(P<0.001)$ existed between INC20R3 and INC20R1.

Table 3. Treadmill peak speed analysis

\begin{tabular}{|l|l|l|l|l|}
\hline $\begin{array}{l}\text { Treadmill } \\
\text { Settings }\end{array}$ & $\begin{array}{l}\text { Peak Speed } \\
(\mathrm{m} / \mathrm{s})\end{array}$ & $\begin{array}{l}\text { Treadmill } \\
\text { Settings }\end{array}$ & $\begin{array}{l}\text { Peak Speed } \\
(\mathrm{m} / \mathrm{s})\end{array}$ & $\mathrm{P}$ value \\
\hline INC15R8 & $6.73 \pm 0.38$ & INC15R5 & $7.21 \pm 0.40$ & $\mathrm{P}<0.001^{*}$ \\
\hline INC15R8 & $6.73 \pm 0.38$ & INC20R3 & $7.64 \pm 0.30$ & $\mathrm{P}<0.001^{*}$ \\
\hline INC15R8 & $6.73 \pm 0.38$ & INC20R1 & $8.12 \pm 0.28$ & $\mathrm{P}<0.001^{*}$ \\
\hline INC20R3 & $7.64 \pm 0.30$ & INC15R5 & $7.21 \pm 0.40$ & $\mathrm{P}<0.001^{*}$ \\
\hline
\end{tabular}




\begin{tabular}{|l|l|l|l|l|}
\hline & & & & \\
\hline INC20R1 & $8.12 \pm 0.28$ & INC15R5 & $7.21 \pm 0.40$ & $\mathrm{P}<0.001^{*}$ \\
\hline INC20R3 & $7.64 \pm 0.30$ & INC20R1 & $8.12 \pm 0.28$ & $\mathrm{P}<0.001^{*}$ \\
\hline
\end{tabular}

Data are Means \pm SD *Denotes Significance $p \leq 0.008$

\section{DISCUSSION}

Speed tests such as the $36.58 \mathrm{~m}$ dash, has provided a baseline for comparing football players in regards to performance. ${ }^{11}$ Sprinting enhancement and training have shown translation to acceleration and contact reaction forces in the sequence of football specific movements. ${ }^{12,13}$ Speed training has been designed to aid in sustained acceleration and peak velocities. ${ }^{11,13}$ Research trends of the manual treadmill have examined the declined biomechanical stresses that may surface when compared to resisted ground sprints..$^{14}$ Reduced stresses and injuries that may be associated with maximum sprinting speeds was considered in regards to the treadmill training. The manual treadmills may target the muscles previously shown to play dominating roles in sprinting, with less stress. ${ }^{15}$ The hamstring muscles have been key in running performance for several reasons including increased ground reaction force and impulse during the sprinting motion..$^{15,16}$ Injuries to this area has been one of the most frequent lower limb injuries, due to the high stresses placed on the muscles during sprinting. Weaker hamstring muscles have negated many other functions associated with sprinting. ${ }^{17}$

Therefore, manual treadmills have been utilized more frequently when compared to solely ground force training. The ability to adjust settings has also manipulated eccentric loads of the running motion. These eccentric movements may provide further strength to the hamstrings and impact ground reaction force during sprinting performance. ${ }^{18-20}$ As hypothesized, the slowest mean peak time of $6.73 \pm 0.38 \mathrm{~m} / \mathrm{s}$ was exhibited during INC15R8, supporting the effectiveness of the manual settings to provide the greatest amount of resistance. Also as hypothesized, the fastest mean peak time of $8.12 \pm 0.28 \mathrm{~m} / \mathrm{s}$ was exhibited during INC20R1, supporting the effectiveness of the manual settings to provide the least amount of resistance. Finally, it is worth noting, that bouts of the same incline, but different resistance also demonstrated significant differences in peak speeds, supporting the effectiveness of the manual settings to provide adequate resistance only.

\section{CONCLUSION}

These findings warrant additional research in non-curved, manual treadmills, as it is evident how essential speed is for football performance. ${ }^{2}$ These finding are extremely important, as these settings play a role in different aspects of sprinting, including phases of acceleration and maximum speed. As with all treadmill training, safety is a key component in programming. Therefore, showing the effectiveness of different settings to elicit altered training speeds is key in a safe and progressive off-season speed program.

\section{REFERENCES}

1. Fitzgerald CF, Jensen RL. A Comparison of the National Football League's Annual National Football League Combine 1999-2000 to 2015-2016. J Strength Cond Res. 2018.

2. Hedlund DP. Performance of Future Elite Players at the National Football League Scouting Combine. J Strength Cond Res. 2018;32(11):3112-3118.

3. Mann JB, Ivey PA, Mayhew JL, Schumacher RM, Brechue WF. Relationship Between Agility Tests and Short Sprints: Reliability and Smallest Worthwhile Difference in National Collegiate Athletic Association Division-I Football Players. J Strength Cond Res. 2016;30(4):893-900.

4. Condello G, Schultz K, Tessitore A. Assessment of sprint and change-of-direction performance in college football players. Int J Sports Physiol Perform. 2013;8(2):211-212.

5. Sanders G, Roll B, A. Peacock C. Maximum Distance and High-Speed Distance Demands by Position in NCAA Division I Collegiate Football Games. Vol 312017.

6. Robbins DW, Goodale TL, Kuzmits FE, Adams AJ. Changes in the athletic profile of elite college American football players. J Strength Cond Res. 2013;27(4):861-874.

7. Sjokvist J, Sandbakk O, Willis SJ, Andersson E, Holmberg HC. The effect of incline on sprint and bounding performance in cross-country skiers. J Sports Med Phys Fitness. 2015;55(5):405-414.

8. Slawinski J, Dorel S, Hug F, et al. Elite long sprint running: a comparison between incline and level training sessions. Med Sci Sports Exerc. 2008;40(6):1155-1162. 
9. Hatchett A, Armstrong K, Parr B, Crews M, Tant C. The Effect of a Curved Non-Motorized Treadmill on Running Gait Length, Imbalance and Stride Angle. Sports (Basel). 2018;6(3).

10. Bruseghini P, Tam E, Monte A, Capelli C, Zamparo P. Metabolic and kinematic responses while walking and running on a motorised and a curved non-motorised treadmill. J Sports Sci. 2018:1-8.

11. Clark KP, Rieger RH, Bruno RF, Stearne DJ. The National Football League Combine 40-yd Dash: How Important is Maximum Velocity? J Strength Cond Res. 2019;33(6):1542-1550.

12. Robbins DW. Relationships between National Football League combine performance measures. J Strength Cond Res. 2012;26(1):226-231.

13. Brechue WF, Mayhew JL, Piper FC. Characteristics of sprint performance in college football players. J Strength Cond Res. 2010;24(5):1169-1178.

14. Macadam P, Cronin JB, Feser EH. Acute and longitudinal effects of weighted vest training on sprint-running performance: a systematic review. Sports Biomech. 2019:1-16.

15. Morin JB, Edouard P, Samozino P. Technical ability of force application as a determinant factor of sprint performance. Med Sci Sports Exerc. 2011;43(9):1680-1688.

16. Morin JB, Gimenez P, Edouard P, et al. Sprint Acceleration Mechanics: The Major Role of Hamstrings in Horizontal Force Production. Front Physiol. 2015;6:404.

17. Opar DA, Williams MD, Timmins RG, Hickey J, Duhig SJ, Shield AJ. Eccentric hamstring strength and hamstring injury risk in Australian footballers. Med Sci Sports Exerc. 2015;47(4):857-865.

18. Mendiguchia J, Samozino P, Martinez-Ruiz E, et al. Progression of mechanical properties during on-field sprint running after returning to sports from a hamstring muscle injury in soccer players. Int J Sports Med. 2014;35(8):690-695.

19. Mendiguchia J, Martinez-Ruiz E, Morin JB, et al. Effects of hamstring-emphasized neuromuscular training on strength and sprinting mechanics in football players. Scand J Med Sci Sports. 2015;25(6):e621-629.

20. Kawamori N, Nosaka K, Newton RU. Relationships between ground reaction impulse and sprint acceleration performance in team sport athletes. J Strength Cond Res. 2013;27(3):568-573. 